\title{
The Neuro-Environmental Loop of Plasticity: A Cross-Species Analysis of Parental Effects on Emotion Circuitry Development Following Typical and Adverse Caregiving
}

\author{
Bridget L Callaghan ${ }^{\star, 1}$ and Nim Tottenham ${ }^{1}$ \\ ${ }^{1}$ Department of Psychology, Columbia University, New York, NY, USA
}

\begin{abstract}
Early experiences critically shape the structure and function of the brain. Perturbations in typical/species-expected early experiences are known to have profound neural effects, especially in regions important for emotional responding. Parental care is one species-expected stimulus that plays a fundamental role in the development of emotion neurocircuitry. Emerging evidence across species suggests that phasic variation in parental presence during the sensitive period of childhood affects the recruitment of emotional networks on a moment-to-moment basis. In addition, it appears that increasing independence from caregivers cues the termination of the sensitive period for environmental input into emotion network development. In this review, we examine how early parental care, the central nervous system, and behavior come together to form a 'neuroenvironmental loop,' contributing to the formation of stable emotion regulation circuits. To achieve this end, we focus on the interaction of parental care and the developing amygdala-medial prefrontal cortex (mPFC) network -that is at the core of human emotional functioning. Using this model, we discuss how individual or group variations in parental independence, across chronic and brief timescales, might contribute to neural and emotional phenotypes that have implications for long-term mental health.
\end{abstract}

Neuropsychopharmacology Reviews (2016) 41, I63-176; doi:I0.1038/npp.20I5.204; published online 2 September 2015

\section{INTRODUCTION}

The quality of the child-caregiver relationship, and indeed the amount of parental care provided, are arguably the most significant contributing factors to emotional functioning across the lifespan. Indeed, numerous scientific theories and perspectives, dating from Freud's 'Oedipus Conflict' in the late 1800s (see Freud, 1953) to theories remaining enormously successful and influential today (eg, ethological and attachment theories, parenting styles, and family systems; Gewirtz et al, 1958; Hofer, 1994; Kernberg, 1972) have all ascribed a special importance to the parent-child relationship for understanding emotional development in children. For example, in attachment theory, the ability of the child to form a specific attachment/bond with the caregiver (and, indeed, the nature of that attachment) is believed to lay the foundation for that child's 'internal working model of social relationships.' This working model is proposed to remain with

${ }^{*}$ Correspondence: Dr BL Callaghan, Department of Psychology, Columbia University, 406 Schermerhorn Hall, 1990 Amsterdam Avenue MC 5501, New York, NY 11027, USA, Tel: +1 212851 0231, Fax: +1 212854 3609, E-mail: blc2139@columbia.edu

Received 3 March 2015; revised 6 July 2015; accepted 7 July 2015; accepted article preview online 21 July 2015 the individual throughout their life, affecting their social, emotional, and cognitive development (Ainsworth, 1969; Bowlby, 1969). Importantly, the central tenet of these theories and perspectives (ie, that the relationship between parent and child is the critical foundation upon which emotional health is built) continues to influence the conceptual frameworks for numerous behavioral and psychological treatments for pediatric mental health disorders that are popular today (see, eg, Dadds and Hawes, 2006; Scott and Dadds, 2009; Timmer and Urquiza, 2014).

Considering the substantial body of epidemiological evidence documenting the strong link between early rearing adversity and mental health disorders (see, eg, Green et al, 2010), it is not surprising that the parent-child relationship features so heavily in theories and perspectives on the development of mental health. Recent meta analyses have shown that childhood adversities involving maladaptive family functioning (eg, neglect, parental mental illness, family violence) are known to increase the risk of onset and persistence of emotional disorders in children, with such early adversity accounting for $\sim 45 \%$ of child-onset and $32 \%$ of adult-onset mental health disorders (Green et al, 2010; McLaughlin et al, 2010). Indeed, in a recent cohort of adults presenting for inpatient or outpatient mental health treatment, 
$76 \%$ reported experiencing some form of childhood trauma (commonly neglect; Wota et al, 2014). Importantly, in that same sample, there appeared to be a positive dose-response function, where adults with more frequent childhood trauma reported more severe emotional symptoms.

The mechanisms underlying the strong connection between the early rearing environment and children's emotional development have been the focus of increasing attention, both in human and nonhuman animal studies. This literature, spanning several decades, has combined to suggest that parents are critical for children's emotional development, in part because of the pronounced regulatory effect they have on children's behavior, physiology, and stress reactivity. Some of the initial evidence for this regulatory role of the parents came from the seminal studies of Myron Hofer who identified the rodent mother as a 'hidden regulator' of her pups' behavior and physiology. By separating infant rat pups from their mother for extended periods of time and then observing behavior and physiology of the pups when one component of the maternal stimulus (eg, warmth or milk) was replaced, Hofer demonstrated that different sensory stimuli from the mother were important in maintaining homeostasis in different pup systems (Hofer, 1973a, b, 1994). For example, although waking of the pup appeared to be unaffected by maternal lactation, sleep onset was disrupted in infants pups cared for by a nonlactating dam (Hofer, 1973b). Further studies have since shown that even relatively complex emotional behaviors appear to be under tight maternal regulation in rodents. For example, fear learning in infant rat pups appears to proceed differently under conditions of maternal presence or absence. Specifically, whereas juvenile pups (ie, postnatal day (P) 21 and older) will consistently display aversion to an odor paired with shock, infant pups (ie, P7-10) will instead display approach responses to that odor. Interestingly, rats in a transitional period (ie, P12-15) will display either approach or avoidance behaviors, depending on whether their mother is present during conditioning, approaching the odor when the mother is present and avoiding the odor when she is absent (Moriceau and Sullivan, 2006). These latter data suggest that there may be a sensitive period during which maternal presence can modulate emotional learning early in life that closes as rats reach weaning age.

The human data demonstrating that parents are potent regulators of their children's emotional and physiological reactivity are also compelling (see, eg, Ahnert et al, 2004; Gunnar et al, 1996; see Hostinar et al, 2014 for a comprehensive review of this literature; Nachmias et al, 1996; Seltzer et al, 2010; Spangler and Schieche, 1998). For example, parents can successfully up- and down-regulate their children's behavioral expressions of fear depending on their own emotional output. Specifically, infants were more likely to cross to the deep side of a visual cliff if their mother was expressing positive emotion than when she was expressing negative emotion (Sorce et al, 1985). Similarly, infants and mothers appear to exhibit adrenocortical 'attunement' (ie, similar fluctuations in CORT patterns) across the day (see, eg, Hibel et al, 2014b; Middlemiss et al, 2012; Papp et al, 2009). In addition, the mere presence of a parent can influence children's performance on an affect regulation task, where it was shown to increase levels of inhibitory control (Gee et al, 2014). In contrast, parental presence had no effect on inhibitory control on that same task in adolescence. Parental presence can also inhibit the acquisition of conditioned fears in the child (Egliston and Rapee, 2007). Furthermore, access to a caregiver has been shown to regulate the hormonal response to stress; young females exposed to a Trier Social Stress Test exhibited a faster return to baseline cortisol (CORT) response if they interacted with their mother in person, or even on the phone, immediately after the test (Seltzer et al, 2012). These data support the idea that a sensitive period exists before adolescence in human development, during which time the influence of parents on child emotion functioning and physiological reactivity is amplified (see Figure 1).

In light of the data demonstrating the important modulating effect that parents have on their children's physiology and emotionality, it makes sense that child populations experiencing parental deprivation (eg, parental death, child neglect) are at elevated risk for significant dysregulation within these typically buffered systems. Indeed, children reared under conditions of extreme parental deprivation (orphanages/ institutional settings with extremely high child to caregiver ratios) exhibit higher rates of anxiety disorders, higher anxiety symptomology, and poorer performance on an affect regulation task than noninstitutionally reared children (see, eg, Tottenham et al, 2010a; Zeanah et al, 2009). In addition, infant rats reared under conditions of high maternal stress (produced through drastically reduced nesting material) begin to exhibit odor aversion learning much earlier in development than rats receiving typical maternal care (Moriceau et al, 2009). Similarly, infant rats that were maternally separated early in life exhibit greater fear relapse and longer lasting fear memories than infants with higher levels of maternal presence across rearing (Callaghan and Richardson, 2011, 2012a, 2014; Callaghan et al, 2013).

The research discussed above suggests that parental availability acts in both tonic and phasic ways to regulate the emotional and physiological development of the child. Parental physical presence, parent's emotional expression, and parent's own physiological reactivity act as phasic modulators of child emotional and physiological reactivityregulating the child's internal experiences and behavioral output in different environmental contexts. This phasic regulation may have an important long-term function, helping to calibrate children's set point of emotional and physiological reactivity (Blair and Raver, 2012; Hibel et al, 2014a). In addition, tonic levels of parental care experienced in early life appear to alter rates of child emotional development. That is, early independence from caregivers (such as that caused by institutionalization) appears to reduce parental modulation of child emotion. However, although the important role of the parent in regulating child physiology, behavior, and emotionality now appears well 


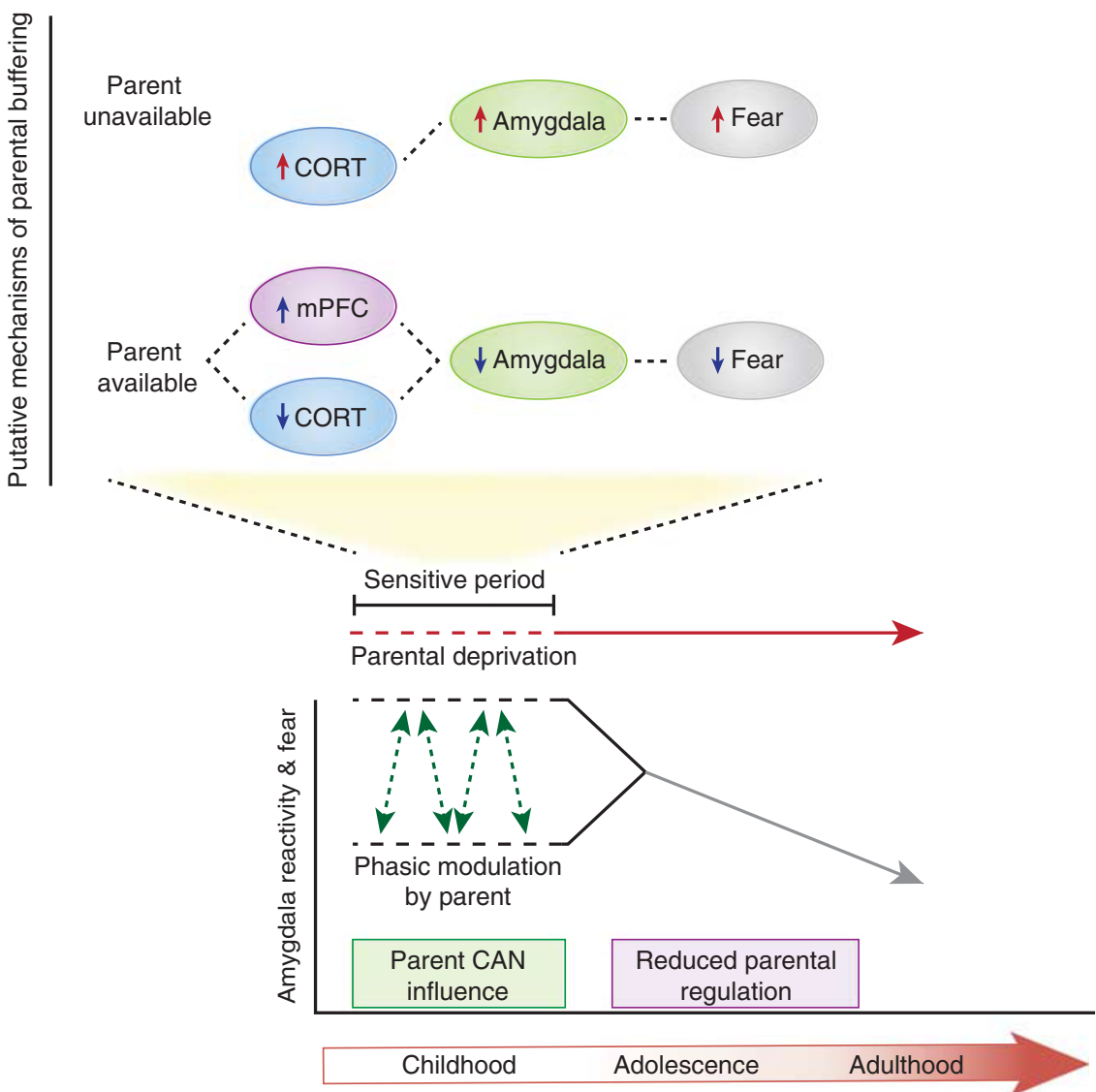

Figure 1. Pictorial depicts how relative independence from parent may act to regulate the timing of the sensitive period of plasticity in the amygdalaprefrontal network. A certain level of parental independence is needed for the sensitive period to open and for the child to experience phasic modulation of the amygdala-prefrontal network via parental buffering. The increased circuit tone that emerges from phasic parental modulation of the circuit would trigger further self-regulation and independence from the parent. Once parental independence begins to exceed a certain threshold, the sensitive period for parental input into amygdala-prefrontal circuitry would decrease-completing the 'Neuro-Environmental' loop.

established, a good understanding of how this effect is mediated at a neurobiological level is still emerging. In this review, we take a cross-species approach to examine how parental availability early in development affects the maturation of emotion neurobiology by focusing on a neural circuit known to be critical to emotional expression and regulation: the amygdala-prefrontal cortex circuit. We start the review by briefly describing the concept of sensitive periods, a notion drawn on regularly throughout the paper. We then state what is known about the development of this circuit, before summarizing the data on phasic parental circuit control. We then examine how amygdala-prefrontal circuitry develops under different levels of tonic parental care, contrasting typical and parental deprivation rearing conditions. In the second half of the review, we explore the idea that parental availability and eventual independence from the caregiver act as a 'Neuro-Environmental Loop,' where parental presence entrains independent functioning of emotion circuits in early life, with the resulting independence cueing the closure of the period for environmental input into emotion circuit development.

Although the current paper focuses on the effects of the postnatal environment on amygdala prefrontal development, it is important to note that parenting influences begin well before birth, influencing the way that offspring respond to postnatal parenting practices. The review of such prenatal effects are outside the scope of the current paper, and interested readers are referred to the following recent studies and literature review (Buss et al, 2012; McEwen and Morrison, 2013; Qiu et al, 2015; Sarkar et al, 2014) on the topic.

\section{SENSITIVE PERIODS OF NEURODEVELOPMENT}

Sensitive periods are commonly conceptualized as epochs of time during which a system is highly plastic and open to environmental restructuring or attunement (see, eg, Hensch, 2005; Werker and Hensch, 2015). A classic example of sensitive period plasticity is the organization of ocular dominance columns in the visual cortex that occurs in numerous species including rats and humans (see Hensch, 2005, for reviews of this literature; Wiesel and Hubel, 1963). Although sensitive periods have traditionally been examined in sensory domains, it is clear that sensitive periods occur throughout the brain in a region-specific analytical level 
(ie, molecules to circuits) and in a time-dependent manner. For example, a growing body of literature has begun to suggest that sensitive periods also occur for emotion development (Callaghan et al, 2014a, b; Callaghan and Richardson, 2014; Gogolla et al, 2009; Tottenham and Sheridan, 2010). In that work, the same molecular and structural signals known to regulate the timing of sensitive period plasticity in the visual cortex, language learning in humans (Werker and Hensch, 2015), and song learning in birds (Balmer et al, 2009) were also shown to regulate the timing of sensitive period plasticity in emotion circuits in humans (see, eg, Callaghan et al, 2014b; Gogolla et al, 2009; Karpova et al, 2011; Nabel and Morishita, 2013). Considering the amygdala-prefrontal cortex is the main neurobiological network underlying emotion regulation, it makes sense to examine whether a sensitive period of plasticity exists in this circuit and, if so, to determine the parameters of such plasticity, including its timing, environmental inputs, and regulators.

\section{THE NEUROBIOLOGY OF EMOTIONALITY}

\section{Amygdala}

Across species, the neurobiology of emotionality has been best characterized at the level of the amygdala. This structure is proposed to be part of a large circuit (also involving the insula, ventral striatum, and ventral regions of the anterior cingulate cortex and prefrontal cortex) involved in identification of emotional salience and production of affective responses to stimuli (Phillips et al, 2003a). As a unitary structure (although comprising a constellation of subnuclei), the amygdala is well known for its importance in emotion perception, learning, and expression. Functional imaging studies, using positron emission technology (PET) and functional magnetic resonance imaging (fMRI), have consistently found greater amygdala reactivity to emotional compared with neutral stimuli, and often with stimuli with a negative valence as opposed to positive valence (see Costafreda et al, 2008 for a meta-analytic review of this literature). Similarly, studies on subjects with bilateral amygdala damage have shown that the amygdala is critical in the auditory and visual recognition of emotions, especially anger and fear (Adolphs et al, 2005; Scott et al, 1997), may help to regulate threat vigilance (Anderson and Phelps, 2001; Terburg et al, 2012), and is critical in decoding ambiguous emotional information (eg, fearful facial expression on a person with an approach bodily stance; de Gelder et al, 2014). In a very recent study, 200 single neuron recordings were taken from the amygdala of neurosurgical patients (presurgery) while they looked at degraded pictures of emotion-expressing faces. Amygdala reactivity was found to track patients' subjective judgments of emotions during that task (Wang et al, 2014), suggesting a specific role for the amygdala in emotion perception, rather than correct emotion identification.

Amygdala also plays a prominent role in fear learning. The amygdala is considered to be the critical structure involved in the formation and storage of conditioned fear associations
(Davis, 1992; LeDoux, 2000; Phelps and LeDoux, 2005), with the lateral nucleus (LA) acting as the site of plasticity and storage for fear memories (see, eg, Davis, 1992; Kwon et al, 2014; LeDoux, 1994; Phelps and LeDoux, 2005), and the central nucleus (CeA) acting as the fear output centerthrough its projections to downstream structures involved in fear expression (eg, paraventricular nucleus (PVN); Krettek and Price, 1978; LeDoux et al, 1988; Veening et al, 1984). In humans too, the amygdala has been consistently implicated in fear conditioning. For example, numerous PET and fMRI studies have shown reliable amygdala activation to the conditioned stimulus (CS+) relative to a nonreinforced stimulus (CS -; see, eg, LaBar et al, 1998; also see Whalen, 1998 for a review), even when those stimuli are presented outside of conscious awareness (Morris et al, 1998). In addition, the level of conditioned fear (measured through electrodermal responses to the $\mathrm{CS}+$ ) is positively associated with regional blood flow in the amygdala (Furmark et al, 1997). Finally, amygdala reactivity has been shown to have predictive clinical utility; amygdala hyperactivity is characteristic of numerous emotional disorders (Phillips et al, 2003b).

\section{Amygdala Development}

Although the past few decades have seen massive advances in our understanding of the structure, physiology, and functioning of the amygdala, the vast majority of this research has been performed in adult humans and nonhuman animals. Despite the known importance of both the amygdala and early-life experiences to emotional functioning, amygdala development remains comparatively underresearched. What is known about amygdala structural and functional development is summarized below.

Although the basic architecture of the human amygdala is present at birth (Humphrey, 1968; Ulfig et al, 2003), it does appear to undergo significant structural and functional remodeling and refinement across the infancy, childhood, and adolescent stages of development (see Tottenham, 2014; Tottenham and Sheridan, 2009 for a review). Although the most rapid postnatal volumetric growth occurs soon after birth (eg, over $100 \%$ increase in volume in $0-1$ year followed by a $9 \%$ increase from years 1 to 2; Gilmore et al, 2012; also see Payne et al, 2010; Uematsu et al, 2012), the amygdala continues to increase in volume until 4 years of age in females and 18 years of age in males (Giedd et al, 1996; Mosconi et al, 2009; Nordahl et al, 2012; Schumann et al, 2004). Amygdala physiology also undergoes significant change early in life. Animal studies have demonstrated continued maturation of the intrinsic properties of amygdala principal neurons (eg, increases in maximal firing and peak resonance frequency; Ehrlich et al, 2012), and of inhibitory neurotransmitter systems within the amygdala (ie, $\gamma$ aminobutyric acid (GABA); Ehrlich et al, 2013) until early adolescence. In terms of functionality, the amygdala exhibits very robust responding to emotional events in childhood, with amygdala reactivity to emotional stimuli then 
decreasing across adolescence and into adulthood (Decety et al, 2012; Gee et al, 2013b; Tottenham, 2012; Vink et al, 2014); however, see Moore et al. (2012) and Hare et al. (2008) for a slightly different outcome. The strong early reactivity in the amygdala parallels the normatively high fear and emotionality that characterizes childhood; indeed, early childhood fears (ie, separation anxiety) are mediated by the excessively high amygdala activity observed during childhood (Gee et al, 2013a, b).

Although human studies are yet to examine the contribution of the amygdala to fear learning early in development, animal studies have shown that amygdala does appear to be involved in aversive conditioning even very early in life. For example, around the time of weaning (P21), rats exposed to olfactory fear conditioning exhibit impaired learning if given amygdala lesions (Sananes and Campbell, 1989). However, before weaning, the amygdala's contribution to olfactory fear learning appears to differ according to age. Specifically, rats normally exhibit a developmental transition in their behavioral responses to an odor paired with shock; under conditions of maternal absence, rats younger than P10 typically exhibit approach responses to the odor, whereas rats conditioned after P10 exhibit odor aversions (see, eg, Sullivan and Wilson, 1993). Importantly, the transition into odor aversion learning is accompanied by increased amygdala reactivity to the shock-paired odor (Sullivan et al, 2000). Critically, this finding parallels human studies demonstrating that the amygdala is relatively less responsive to emotional cues in early infancy (Blasi et al, 2011; Dehaene-Lambertz et al, 2010; Graham et al, 2013). Taken together, these developmental studies suggest that although the amygdala is structurally and functionally immature in childhood, it is clearly activated by emotional tasks and does participate in emotion learning under some circumstances. Importantly, this relative immaturity may have significant implications for the openness of the amygdala to environmental regulation early in life (Lupien et al, 2009).

\section{Prefrontal Cortex}

To the same extent that the amygdala has been implicated in emotion perception and expression, prefrontal cortex (PFC; specifically the medial PFC (mPFC), dorsal lateral PFC (dlPFC), dorsal medial PFC (dmPFC), and ventromedial PFC regions (vmPFC), as well as the orbital frontal cortex (OFC) and the anterior cingulate cortex (ACC)) has been implicated in emotional regulation. Specifically, the PFC is believed to exert top-down inhibitory control over amygdala reactivity, resulting in a dampening of emotional responding (Milad et al, 2006). Rodent studies have demonstrated both structural and functional connections between amygdala and mPFC (McDonald et al, 1996; Quirk et al, 2003), and have shown that mPFC lesions (specifically of the infralimbic region (IL)) result in impaired extinction retention, while leaving extinction learning intact (Milad and Quirk, 2002; Quirk et al, 2000). Similarly, in humans, recall of extinguished fear memories increases vmPFC reactivity in response to the CS+ (Milad et al, 2007; Phelps et al, 2004), and is positively associated with vmPFC thickness (Milad et al, 2005). In addition, on a different emotion regulation task involving cognitive reappraisal of a negative event, the amygdala showed stronger coupling with the dlPFC, OFC, subgenual ACC, and dmPFC, with the extent of such coupling being positively associated with post-reappraisal attenuation of negative affect (Banks et al, 2007; Ochsner et al, 2002; Urry et al, 2006). Indeed, weak amygdala-mPFC connections result in pathological emotional overarousal (Milad et al, 2008, 2009; Motzkin et al, 2015). Hence, in adults, there is clear evidence for the role of prefrontal regions in emotion regulation and control of amygdala output.

\section{PFC Development}

In humans, the PFC exhibits protracted structural development. For example, maximum synaptic density in the PFC lags 4 years behind visual cortex, and the dlPFC is one of the last cortical regions to achieve adult thickness (Lenroot and Giedd, 2006). Functional connections between amygdala and PFC are also late emerging. Research in typically developing populations has shown that amygdala-mPFC functional connectivity during a passive viewing emotional task changes dramatically across development, moving from a positive functional connection in childhood to a mature and negative connection in adolescence that more closely fits the top-down regulatory profile proposed for this circuit in adults (Gee et al, 2013b). Functional connectivity between amygdala and PFC has also been shown to increase across age during a moral or emotional judgment task (Decety et al, 2012; Vink et al, 2014). Similarly, functional connectivity between amygdala and mPFC during rest also exhibits profound developmental change. Specifically, amygdala connectivity with mPFC changes from nonsignificant coupling to being positively coupled, as children transition into adolescence ( $\sim 10.5$ years of age; Gabard-Durnam et al, 2014; NB: patterns of resting connectivity are often opposite in valence to task-based patterns, suggesting that resting connectivity may function to prime the circuit for expected connectivity patterns during tasks). In addition, structural integrity of the uncinate fasciculus (the major white matter tract connecting the PFC and amygdala) increases across age and predicts reduced amygdala reactivity to pictures of emotion-expressing faces (Swartz et al, 2014). Importantly, the maturation of prefrontal cortical regions and increase in connectivity between amygdala and PFC also appears to have direct consequences for emotional functioning in childhood. With increasing age, excessive fears decline and this effect is mediated by amygdala-mPFC connectivity (Gee et al, 2013b).

The role of the PFC during active emotion regulation has only recently been investigated across typical development. For example, using an emotional 'go-no-go' task (requiring behavioral regulation in an affective context) amygdalavmPFC functional connectivity was shown to be essentially 'adult-like' in adolescents (Hare et al, 2008). In another 
study, negative emotion regulation was examined using a cognitive reappraisal task that involved reinterpreting emotional responses to stimuli (McRae et al, 2012). In a sample of 10-22 year olds, age-related increases in reappraisal effectiveness and in recruitment of $\mathrm{mPFC}$ regions during reappraisal were observed. In another reappraisal study investigating amygdala-mPFC connectivity in a sample of 10-22 year olds, all individuals demonstrated a decrease in negative affect when using reappraisal strategies that improved as a function of age (Silvers et al, 2014). In addition, older age was found to predict increasingly negative connectivity between the amygdala and rostrolateral PFC during the reappraisal task, an effect consistent with the prior functional research demonstrating increasingly negative amygdala-mPFC coupling across age (Gabard-Durnam et al, 2014; Gee et al, 2013b). Importantly, age also predicted larger decreases in amygdala response during emotional reappraisal, consistent with the role of the PFC as a topdown regulator of amygdala reactivity.

Studies in developing rodents too support a slow emerging role for the PFC in emotion regulation. For example, temporary inactivation of the IL before extinction training impairs extinction retention in adults but has no effect on extinction retention in infants (Kim et al, 2009; SierraMercado et al, 2010). Adolescent rodents, on the other hand, do use the IL mPFC when extinguishing fear but appear to require additional extinction training to sufficiently recruit the IL and allow good retention of extinguished fear (Kim et al, 2011; McCallum et al, 2010). Hence, even in rodents, there appears to be a developmental lag in the recruitment of amygdala-prefrontal circuits during emotion regulation. This late onset of amygdala-mPFC functional connectivity may mirror the ecology of the developing child. During a time when parents are often readily available, it may be ontogenetically unnecessary (and even inefficient) to activate this system early. That is, it is possible that the parent may help to regulate the amygdala at a time when the PFC is not yet functionally mature. Emerging evidence appears to support this role of parents in phasic modulation of amygdala reactivity and in aiding emotional regulation.

\section{PHASIC PARENTAL MODULATION OF AMYGDALA-PREFRONTAL CIRCUITS}

As reviewed in the Introduction, it is now well established that parents act to buffer their children's emotional and physiological reactivity (reviewed in Hostinar et al, 2014). Interestingly, increasing evidence suggests that parents may achieve this emotional and physiological 'buffering' via the amygdala. In a series of eloquent rodent studies, Sullivan and colleagues (Moriceau and Sullivan, 2006) demonstrated that the maternally mediated transition between learned approach and avoidance responses to odor-shock conditioning in transitional period rat pups (ie, P12-15) was regulated by the mother's effect on amygdala corticosterone (CORT). Specifically, odor-shock conditioning of transitional period pups resulted in olfactory bulb activation and odor approach if the mother was present. However, if the mother was absent, the same conditioning procedure resulted in increased amygdala activation, increased amygdala CORT, and an odor aversion (Moriceau and Sullivan, 2006). Temporary inactivation of the amygdala during odor-shock conditioning in maternal absence prevented aversion learning, suggesting that amygdala activity is necessary to produce conditioned aversion responses. Finally, direct infusions of CORT into pup's amygdala during conditioning with mother present resulted in robust odor aversion learning, suggesting that amygdala CORT is normally decreased by maternal presence to allow learned approach responses. Subsequent studies have demonstrated that CORT-induced increases in amygdala dopamine are important in development of odor aversions, suggesting that maternal presence may also suppress amygdala dopamine levels during the transitional period (Barr et al, 2009). Importantly, across the studies just cited, the maternal buffering effect seen in sensitive period rodents was not observed in pups that were older than the sensitive period age. These data suggest that there is specificity in the sensitive period for maternal buffering to infancy stage in the rodent.

Although the role of $\mathrm{mPFC}$ has not been investigated in the rodent maternal buffering model, it has been suggested that mPFC is likely important for stress buffering effects (see Hostinar et al, 2014 for a review of these data). That is, although $\mathrm{mPFC}$ does not appear to spontaneously regulate amygdala reactivity early in life, it may do so during conditions of parental presence. Indeed, maternal presence has been shown to increase mPFC activity during a stressful procedure in juvenile macaques (Rilling et al, 2001), and lesions of the mPFC impair the dampening of physiological reactivity in this species (Herman et al, 2005). In addition, $\mathrm{mPFC}$ activity was shown to be higher in parental presence than under conditions of parental absence in the developing rodent Octodon degu (Bock et al, 2012).

Interestingly, across human development, amygdala reactivity also appears to be more responsive to parental input in childhood than in adolescence, with parental regulation of mPFC activity appearing to contribute to amygdala dampening. Specifically, right amygdala activity (which is typically high in childhood) was suppressed when children were viewing pictures of their mother, relative to when viewing pictures of a stranger (Gee et al, 2014). Critically, there was no difference in right amygdala reactivity in adolescents viewing pictures of mothers and strangers. In addition, amygdala-mPFC functional connectivity was stronger in children when they were viewing pictures of mothers than when they were viewing pictures of a stranger; a similar pattern of amygdala-mPFC connectivity was observed in adolescents regardless of which stimuli were being viewed (mothers or strangers). These data suggest that the pictures of the parent phasically activated a more mature profile of connectivity between amygdala and mPFC in children, driving amygdala reactivity down. Importantly, the recruitment of mature amygdala-mPFC circuitry during the maternal picture condition had positive psychological effects, 
whereby children and adolescents with the negative connectivity pattern had lower separation anxiety and greater attachment security. Finally, buffering of amygdala reactivity by maternal stimuli also appeared to be positively related to affect-related inhibitory control of children (but not adolescents who already had good inhibitory control in that domain); that is, on a task that involved pressing buttons to emotion-expressing faces, fewer false alarms were made by children when they were seated next to their mother, relative to when sitting next to a stranger, and this effect was greater in individuals who showed stronger buffering of amygdala reactivity to maternal cues.

More evidence for parental buffering of amygdala-mPFC circuitry in humans can be found in a fMRI study of youths viewing physical threat words (Conner et al, 2012). Parental presence was found to normalize neural activity in the hypothalamus, vlPFC, and vmPFC of anxious youths to the level of healthy control youths. Although the age range in that study was not wide enough to make any conclusions regarding the differential role of parental presence in children versus adolescents, they are largely consistent with the view that parental presence can have dramatic effects on the recruitment of emotion circuits during early life.

Importantly, across species, it appears that the modulatory effects of the mother on amygdala reactivity only occur during a sensitive period of development (postnatal day 1215 in the rodents; childhood in the humans and monkeys). This sensitive period appears to coincide with a stage of considerable amygdala maturation (see, eg, Ehrlich et al, 2012 , 2013), fitting with the idea that periods of rapid growth open up opportunities for environmental input into system functioning and development (Lupien et al, 2009). Importantly, the termination of this sensitive period appears to coincide not only with increased age-associated neural maturation but also with the increased independence from parents as individuals approach adolescence.

Taken together, the studies described so far collectively show that childhood is a developmentally unique period for parental buffering of CORT, emotional responding, amygdala reactivity, and amygdala-mPFC connectivity (see, eg, Decety et al, 2012; Egliston and Rapee, 2007; GabardDurnam et al, 2014; Gee et al, 2013b, 2014; Hibel et al, 2014b; Middlemiss et al, 2012; Moriceau and Sullivan, 2004, 2006; Papp et al, 2009; Seltzer et al, 2010, 2012; Silvers et al, 2014; Sorce et al, 1985; Sullivan et al, 2000; Swartz et al, 2014; Vink et al, 2014). Importantly, we believe that the role of the parent in phasic modulation of the amygdala and mPFC is critical for circuit tone and for the long-term effectiveness of the circuit in emotion regulation. Specifically, in childhood, parental presence has a buffering effect on CORT, suppresses amygdala reactivity, and increases functional connectivity between the amygdala and mPFC, thereby instantiating a mature profile of connectivity between these brain regions; amygdala reactivity decreases as $\mathrm{MPFC}$ reactivity increases (see Figure 2). We propose that this coincidental activation of amygdala and mPFC under conditions of parental presence 'entrains' the amygdala and mPFC to connect in

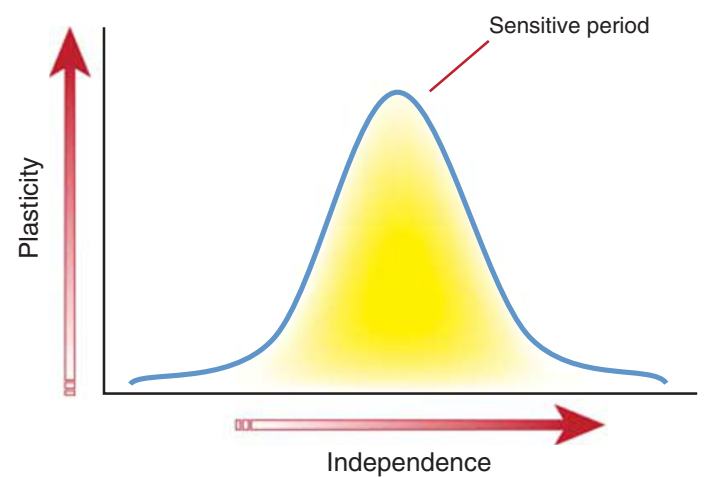

Figure 2. A proposed mechanism for parental buffering and putative consequences for the amygdala-prefrontal network. Within the childhood sensitive period (during typical development), parents can buffer amygdala reactivity and fear responses. In other words, during the sensitive period, mPFC reactivity is proposed to increase in physical parental presence, whereas cortisol levels, amygdala reactivity, and fear responses are decreased. In parental absence, however, we propose that the mPFC is not activated, and that cortisol levels, amygdala reactivity, and fear are increased. Hence, variations in parental presence and absence during the sensitive period phasically modulate and tone the amygdala and MPFC to begin to function as a regulatory network. The increased circuit tone is proposed to mediate age-related reductions in amygdala reactivity seen as children transition into adolescence. Children who have experienced parental deprivation exhibit accelerated termination of the critical period and less opportunities for circuit tone. Hence, it is proposed that amygdala reactivity and fear remain high following deprivation.

a way that supports top-down control of amygdala activity, thereby contributing to long-term regulatory connectivity in the network.

Indeed, the idea that environmental experience can 'entrain' network connections does appear to have precedence in the adult literature. For example, long-term changes in functional connectivity within a neural circuit have been shown to occur following learning that activates that circuitry (Harmelech et al, 2013; Lewis et al, 2009; Mackey et al, 2013). In addition, there is evidence that amygdala-prefrontal resting connectivity in developing populations is related to patterns of taskbased activity many years earlier (see Gabard-Durnam et al, 2014). We envision a very similar mechanism for parental entraining of amygdala-prefrontal connectivity, ie, we believe that the environmental experience of being with a parent acts as a 'neuro-scaffold' that lays out the blueprint by which stable patterns of brain connectivity are shaped.

A scaffold-like mechanism for developing connectivity in the amygdala-mPFC circuit would suggest that the more experience one has with parental modulation of emotion during the sensitive childhood period, the greater the regulatory capabilities of the circuit (and, therefore, the better the self regulatory capacities of the individual) will be after the sensitive period. Inversely, this mechanism also suggests that parental absence/unavailability during the sensitive period, or an inability of parental presence to result in amygdala buffering during the sensitive period, may contribute to impoverished functional/structural connections in the circuit, potentially contributing to heightened amygdala reactivity and enhanced emotionality across the 
lifespan. Indeed, emerging data in rodents as well as humans who have experienced early parental deprivation support this theory.

\section{EFFECTS OF CHRONIC PARENTAL DEPRIVATION ON AMYGDALA-PREFRONTAL DEVELOPMENT}

The ability of the parent to modulate fear neurobiology depends on developmental plasticity in childhood. However, emerging evidence suggests that developmental plasticity may not be a consistent feature of childhood. Rather, these data appear to suggest that the developmental trajectories of emotion regulation circuits (ie, from plastic to stable) appear to be accelerated under certain early rearing environments, specifically, those of adversity. For example, studies in rodents have shown that when maternal care is fragmented early in life (eg, when reduced nesting material is given to the mother, causing her to have to regularly rebuild the nest) rats make an early transition from approach to avoidance behaviors following odor-shock learning, an effect accompanied by increased amygdala reactivity during conditioning (Moriceau et al, 2009). In other words, it appears that the developmentally sensitive period for maternal dampening of amygdala responding and fear learning may have ended early following a period of rearing under fragmented care conditions. Similarly, early separation from the mother (because of precocious weaning) has been shown to accelerate amygdala myelination in mice (Ono et al, 2008); increased myelin is considered to act as a brake on plasticity, resulting in circuit stabilization (McGee et al, 2005). In yet another study in mice, infant isolation lead to an early switch in the signaling cascades for long-term potentiation in the hippocampus (from PKA dependent to CAMKII dependent), a change that is critical for adult-like memory expression (Huang et al, 2005). Other researchers have shown that behaviors associated with amygdala-mPFC connectivity (ie, fear conditioning and extinction) have accelerated developmental trajectories following early adverse rearing. Specifically, maternal separation for the first 2 weeks of life resulted in preweaning rats exhibiting relapse following extinction and longer lasting fear memories, behaviors normally only seen in rats after weaning (Callaghan and Richardson, 2011, 2012a; for a review see Callaghan and Richardson, 2012b). Similarly, early exposure of rats to the stress hormone CORT also resulted in an early transition into adult-like fear retention and extinction, suggesting that early stress exposure was a critical component in the effect (Callaghan and Richardson, 2012a, 2014). Hence, animal studies appear to converge on the finding that the developmental change from plastic to stable amygdala-mPFC circuitry is accelerated following chronic parental deprivation. Put another way, the data support the idea that early independence from the parent cues early termination of the sensitive period for environmental input into amygdala-mPFC circuitry.

Although studies in humans cannot directly manipulate the early rearing environment to examine the outcomes of parental deprivation on developing amygdala-prefrontal circuitry, some studies in humans have taken advantage of preexisting instances of parental deprivation to study these effects. For example, individuals reared in institutions (such as orphanages) from early in life experience the very rare occurrence of chronic parental absence. This lack of parental care ends when stable families adopt the institutionalized youth, creating a sample of previously institutionalized (PI) individuals with a history of parental deprivation restricted to early life. Interestingly, as predicted by findings from rodent models of fragmented or separated care, PI individuals appear to exhibit accelerated termination of the sensitive period for plasticity within amygdala-mPFC circuitry. Specifically, whereas typically reared individuals exhibit a switch in amygdala-mPFC connectivity from positive coupling in childhood to negative coupling in adolescence, PI individuals exhibit negative coupling even as children (Gee et al, 2013a). That is, PI children appear to exhibit the mature profile of connectivity (ie, reflecting stable circuit function) earlier in development. Importantly, this early maturation may serve a functional purpose, at least in the short term; PI individuals who exhibited the negative (mature) connectivity profile also exhibited better emotion regulation than PI youths with positive connectivity.

Although no other human studies have directly examined the role of parental deprivation on amygdala-prefrontal circuit development (see Bick et al, 2015 for a comprehensive analysis of white matter development following early deprivation that may relate to amygdala-mPFC structural connectivity), some studies have shown that other forms of early-life adversity, eg, maltreatment or psychopathology experienced in childhood or before early adolescence, may also be associated with accelerated amygdala development. For example, higher rates of childhood adversity were associated with larger (ie, more mature) left amygdala volume in early adolescence (Whittle et al, 2013), as was adolescent-onset depression (another condition that disrupts the early rearing environment; Whittle et al, 2014). In addition, children exposed to maternal depression since birth had larger amygdale than same-aged peers without depressed mothers (Lupien et al, 2009). Interestingly, the effect of prenatal stress on amygdala volume is similar to the postnatal stressors reported here (ie, higher right amygdala volume was reported in female children of mothers with higher maternal cortisol in early gestation and was associated with more affective problems in those girls during childhood; Buss et al, 2012). Hence, other forms of adversity that would conceivably affect or be affected by the early rearing environment/parent-child relationship may also be associated with accelerated amygdala development (but see the following studies of decreased amygdala volume following early adversity: Hanson et al, 2015; Luby et al, 2013).

The data discussed above are compelling in that they converge on the finding that, across species, early deprivation of caregiving stimuli/adversity in the caregiving environment result in accelerated closure of the sensitive period for amygdala structural and functional development, 
amygdala-mPFC functional connectivity, and behaviors dependent on mature amygdala-mPFC functional connectivity, namely, adult-like fear conditioning and extinction (for a review see Callaghan et al, 2014a).

If the sensitive period of amygdala-mPFC circuit plasticity is terminated early following conditions of adverse rearing, we might expect to see an impairment in the phasic regulation of amygdala-mPFC circuitry in PI youths under conditions of (adoptive) parental presence. That is, like typically reared adolescents, parental input may be less effective in regulating amygdala-mPFC circuitry in PI children. However, unlike typically reared adolescents, PI children exhibiting an early closure of the sensitive period would have had less opportunity for phasic parent-induced amygdala-mPFC functional coactivation early in development while the network was still maturing (ie, phasic regulation requires high plasticity in childhood that does not occur following chronic deprivation of parental care). Considering that patterns of brain activation during learning or practice are often recapitulated during rest to create stable networks in adults (see, eg, Harmelech et al, 2013), it is possible that chronic parental deprivation, resulting in low coactivation between amygdala and mPFC during that circuit-sensitive period of development, may have longterm effects on the integrity of the circuit. Specifically, in the long term, we anticipate that amygdala reactivity would be chronically higher, and regulation of amygdala reactivity by the mPFC may be poorer across the lifespan following chronic early deprivation (see Figure 2), a feature that is characteristic of anxiety disorders (see, eg, Hahn et al, 2011; Kim and Whalen, 2009; Monk et al, 2008). Although the hypothesized role of chronic parental deprivation on phasic parental buffering of amygdala reactivity has not yet been directly tested, it is supported by the numerous studies across species that have demonstrated accelerated amygdala-mPFC development following parental deprivation/rearing stress (reviewed above).

\section{A NEURO-ENVIRONMENTAL LOOP OF PLASTICITY: A SENSITIVE PERIOD FOR ENVIRONMENTAL INFLUENCE ON AMYGDALA-PREFRONTAL CIRCUITRY}

We have reviewed evidence that amygdala-prefrontal maturation and associated emotional regulation skills exhibit a protracted developmental trajectory that is ubiquitous across species. Specifically, it appears that the circuit moves from being relatively unresponsive to environmental regulation in infancy, to being highly malleable to parental input in childhood, before again reducing parental input in adolescence (Blasi et al, 2011; Dehaene-Lambertz et al, 2010; Gabard-Durnam et al, 2014; Gee et al, 2013b, 2014; Graham et al, 2013; Moriceau et al, 2009). Critically, the same environmental experience of parental deprivation appears to have a similar effect on the maturation of the circuit across species, leading to accelerated closure of the sensitive period for environmental input into amygdala-mPFC development
(Callaghan and Richardson, 2011, 2012a, 2014; Gee et al, 2013a; Moriceau et al, 2009). These features of the system suggest a sensitive period of plasticity is open across childhood to allow the shaping of amygdala-mPFC circuitry by speciesexpected environmental experiences-ie, parental care.

One of the best-characterized molecular regulators of plasticity is GABA inhibition. An optimal level of GABAergic inhibition within the visual cortex is required before the sensitive period is opened. Once that threshold is reached, continued development of the GABAergic system results in the formation of structural brakes on plasticity (such as perineuronal nets) that terminate the sensitive period (Hensch, 2005; Hensch and Fagiolini, 2005; Hensch et al, 1998). Here we suggest a similar mechanism for an environmental signal to dynamically regulate the timing of sensitive period plasticity in the amygdala-mPFC systemparental independence. Specifically, we propose that levels of caregiver independence across the infancy, childhood, and adolescent periods of development are directly related to plasticity within the amygdala-mPFC network (see Figure 2 for a graphical depiction of this idea). Within this model, complete dependence on the caregiver at birth inhibits environmental regulation of amygdala activity (Blasi et al, 2011; Dehaene-Lambertz et al, 2010; Graham et al, 2013). With the onset of motor independence (eg, competent walking), optimal levels of parent-child dependence are neared and the sensitive period for environmental input into emotion regulation and amygdala-mPFC circuitry is opened. Then, as independence from the caregiver gradually increases, the sensitive period for environmental input into amygdala-mPFC development begins to close, leading to relative circuit stabilization. Importantly, this model predicts that individuals who experience premature caregiver independence (eg, those reared in institutional settings or exposed to chronic parental neglect) will exhibit an early closure of the sensitive period for amygdala-mPFC plasticity; an outcome that is well established in rodent literature (Callaghan and Richardson, 2012b, 2014; Moriceau et al, 2009; Ono et al, 2008) and is increasingly accepted to occur in humans (Gee et al, 2013a).

Understanding parental regulation of amygdala-mPFC plasticity within the framework of sensitive periods also fits well within the larger social buffering literature. Specifically, it is well known that social buffering occurs across the lifespan, with different individuals being more effective 'buffers' at different stages of development. For example, having a best friend present during a stressful experience had a cortisol buffering effect in early adolescent males and females (Adams et al, 2011). In addition, romantic partners can buffer stressful experiences (either psychologically or physiologically) in adulthood (Ditzen et al, 2007; Kirschbaum et al, 1995). Although social buffering exerts important effects on emotional functioning across the lifespan, we argue that the consequences of social buffering on the long-term effectiveness of the amygdala-prefrontal circuit differ according to whether they occur within or outside of the sensitive period (with buffering occurring 
within the sensitive period being most effective for long-term circuit function), such that social buffering by the parent during a sensitive period has enduring effects on the structure and functioning of the circuitry. Indeed, learning in adulthood has been shown to recapitulate many sensitive period mechanisms of the visual cortex, although to a lesser extent and on a more local timescale than what occurs within the sensitive period (Donato et al, 2013).

If it is the case that caregiver independence acts as a termination signal for amygdala-mPFC plasticity, then increasing independence should be associated with the arrival of molecular brakes on plasticity. Indeed, the transition into adolescence (a period of increased independence from the caregiver) is associated with increased white matter or myelin (Paus, 2005). In addition, early caregiver weaning in the rodent is associated with higher levels of myelin-associated proteins in the amygdala (Ono et al, 2008). One recent study has examined white matter development following institutionalization and demonstrated decreased fractional anisotropy values (a putative measure of myelin integrity) in numerous fiber tracts across the brain (Bick et al, 2015). Importantly, however, the main fiber tract connecting the amygdala and mPFC - the uncinate fasciculus-did not appear to be affected by the experience of deprivation, leaving open the question of whether PI groups may actually show accelerated white matter development in that tract.

Although numerous important and useful models describe the role that early experiences (such as adversity) play in neural development (see, eg, Lupien et al, 2009; McEwen, 2004), exactly how parents (and other important environmental signals) regulate the maturation of emotion neurobiology requires elaboration. Using the critical period framework we propose a model-the 'Neuro-Environmental Loop' (see Figure 2)-that describes the intersection between parental care, independence, emotion neurobiology, and behavior. Within this model, an optimal level of caregiver dependence is achieved during childhood, where the child is capable of exploring their own environment but looks to the parent for emotional support and guidance. We propose that this semiindependence acts as a signal to open amygdala-mPFC circuit plasticity (ie, the sensitive period). In turn, phasic parental presence during the sensitive period (as the child vacillates between independent exploration and parental care) acts to modulate and tone the circuit by engaging mature connectivity patterns between amygdala and mPFC (ie, suppression of amygdala and increases in mPFC reactivity) when in parental presence. We propose that the functional activation of regulatory circuitry under conditions of parental presence in childhood strengthens the long-term regulatory connections between the two structures. In other words, phasic parental availability entrains the development of stable regulatory connections within the plastic circuit. Based on previous research demonstrating the effect of parents on CORT levels and the importance of CORT in parental buffering of fear learning (Gunnar and Donzella, 2002; Moriceau et al, 2004, 2006), we propose that the phasic role of the parent in mature
amygdala-mPFC tone probably occurs via the pathway of parental suppression of CORT levels.

As the regulatory emotional circuit is increasingly stabilized by parental phasic modulation during the sensitive period, we propose that children would exhibit increasing levels of parental independence. Importantly, once displayed independence surpassed an optimal level (see Figure 1), the sensitive period for environmental input into amygdalamPFC functioning would be terminated. Put another way, independence acts as a negative feedback signal to shut off plasticity within the amygdala-mPFC circuit. Critically, if the level of independence from parents is surpassed early in development (ie, following chronic deprivation from the caregiver), then termination of the sensitive period would also occur earlier. Hence, the 'Neuro-Environmental Loop' can account for both typical and deprivation-induced patterns of amygdala-prefrontal development.

Importantly, although the transition from parental dependence to parental independence is proposed as a critical regulator of sensitive period timing in the current model, we do not suggest that such dependence levels are the only modulators of timing. Pubertal maturation, physical growth, and the social environment (eg, school initiation, driving, etc), are all factors likely to feed into the timing of neural development, and may also act as signals for greater levels of independence. That is, parent-child distance is likely to increase through parentmotivated mechanisms (eg, perceived increases in child physical and emotional growth), child-motivated mechanisms (eg, greater socialization outside of the home, motor independence), as well as social factors (eg, school entry).

It has long been recognized that the parent-child relationship has significant effects on the emotional functioning of the child (Ainsworth, 1969; Bowlby, 1969; Green et al, 2010; McLaughlin et al, 2010). Experimental evidence now suggests that one of the main pathways via which the parent-child relationship affects child emotion is parental modulation of CORT and fear (Hostinar et al, 2014). In this paper we have reviewed the emerging evidence demonstrating that parents also buffer emotion circuits in the brain, and that parental deprivation acts to accelerate the termination of the sensitive period within emotion neurobiology. Using the framework of sensitive period plasticity, we have described these effects in terms of a 'Neuro-Environmental Loop', where relative levels of caregiver independence regulate circuit tone and the timing of sensitive period onset and offset. It is our hope that this timely model can be used to guide future research in this burgeoning field. Several predictions to emerge from the model that can be examined in future research are discussed in the following section.

\section{FUTURE RESEARCH DIRECTIONS}

One prediction to emerge from the neuro-environmental loop model of plasticity relates to the 'cost' of accelerated amygdala-mPFC development. Specifically, we would predict that early closure of the sensitive period would create 
vulnerability within the amygdala-mPFC circuit that may become most evident later in development, or with additional emotion regulation challenges. Actually, there is some evidence demonstrating that vulnerability may exist in this circuit following early sensitive period closure. For example, higher rates of internalizing and externalizing symptoms are observed in previously institutionalized youth (Tottenham et al, 2010b; Zeanah et al, 2009). A related prediction is that accelerated maturation of the amygdalamPFC network may impose a cost on concurrently or future developing neural structures or circuits. Indeed, chicks exposed to early visual stimulation exhibit accelerated visual development at the expense of auditory maturation (Lickliter, 2004). In the humans, there are numerous possible candidate brain regions that might be affected by early amygdala-mPFC development. As just one example, prefrontal and cerebellar regions appear to exhibit similarly protracted developmental profiles (Diamond, 2000), and the same deprivation experience that is associated with accelerated amygdala-mPFC functional connectivity also results in early impairments in cerebellar functions (ie, balance and bilateral coordination; Roeber et al, 2014). Hence, it is possible that accelerated development in emotion circuitry following parental deprivation may be instrumental in producing cerebellar or other circuitry deficits.

Although several components of the Neuro-Environmental Loop model are well supported in the literature, some sections remain speculative and require additional evidence. Specifically, although parental buffering of CORT and fear learning has been demonstrated in humans and rodents (see, eg, Egliston and Rapee, 2007; Gunnar and Donzella, 2002; Moriceau et al, 2006), parental buffering of amygdala reactivity in humans under conditions of physical parental presence requires further investigation. However, considering the parental buffering effect on amygdala reactivity that was achieved through exposure merely to parental stimuli (ie, pictures of the parent; Gee et al, 2014), it is expected that buffering of amygdala reactivity under conditions of physical parental presence will be stronger. In addition, although activation of mature amygdala-mPFC connections has been established during parental presence in humans, rodent models are yet to explicitly verify the role of the mPFC in parental buffering (although the $\mathrm{mPFC}$ is proposed to be important for the effect; see Hostinar et al, 2014 for a review). Although parental buffering of conditioned fear responses is also well established in rodent models, human studies are yet to examine the role of the parent in explicit fear conditioning. Finally, longitudinal designs will be required to establish whether phasic parental modulation of amygdala-mPFC circuitry during the sensitive period is fundamental in circuit tone after the sensitive period. Importantly, animal models would be useful in developing causal evidence for system 'toning' during developmentally sensitive periods. Increasingly sophisticated and targeted molecular manipulations in rodents (eg, optogenetics) could be utilized to mimic maternal effects on amygdala-mPFC reactivity, to determine the timing and dose-response functions of parentally buffered system 'toning' effects.

Although the model proposed in this review makes specific suggestions about future research, a number of more general recommendations can be derived from the body of data as a whole. First, one of the clear benefits in the study of parental buffering/parental deprivation is that there is clear translational validity in not only the phenomena but also the models through which it is studied across species. Many benefits can and have been obtained through the cross-species analysis of parental buffering/deprivation, allowing for greater mechanistic insight and hypothesis-driven research (see Callaghan et al, 2014a for a review). Future studies should aim for greater collaboration between animal and human researchers in this field and more integrated animal-human studies when possible. Such studies will hold great value in identifying avenues for intervention and treatment in the future. Finally, this research highlights the great need for increased longitudinal studies across development. Considering that altered trajectories may have significant effects on circuit integrity and function, examining how a single individual matures across multiple developmental epochs is a powerful means through which trajectory deviation can be established and the developing effects on various systems can be measured across time. With these principles in mind, we look forward to the next decade of research in the field of parental buffering and early adversity.

\section{FUNDING AND DISCLOSURE}

The authors declare no conflict of interest.

\section{ACKNOWLEDGMENTS}

This work was supported by the National Institute of Mental Health grant R01MH091864 (to N Tottenham), the Dana Foundation P50MH078105 (to $\mathrm{N}$ Tottenham), and the National Health and Medical Research Council CJ Martin Early Career Fellowship APP1091571 (to BL Callaghan).

\section{REFERENCES}

Adams RE, Santo JB, Bukowski WM (2011). The presence of a best friend buffers the effects of negative experiences. Dev Psychol 47: 1786-1791.

Adolphs R, Gosselin F, Buchanan TW, Tranel D, Schyns P, Damasio AR (2005). A mechanism for impaired fear recognition after amygdala damage. Nature 433: 68-72.

Ahnert L, Gunnar MR, Lamb ME, Barthel M (2004). Transition to child care: associations with infant-mother attachment, infant negative emotion, and cortisol elevations. Child Dev 75: 639-650.

Ainsworth MD (1969). Object relations, dependency, and attachment: a theoretical review of the infant-mother relationship. Child Dev 40: 969-1025. Classic paper on the infant-mother relationship and attachment.

Anderson AK, Phelps EA (2001). Lesions of the human amygdala impair enhanced perception of emotionally salient events. Nature 411: 305-309.

Balmer TS, Carels VM, Frisch JL, Nick TA (2009). Modulation of perineuronal nets and parvalbumin with developmental song learning. J Neurosci 29: 12878-12885. Banks SJ, Eddy KT, Angstadt M, Nathan PJ, Phan KL (2007). Amygdala-frontal connectivity during emotion regulation. Soc Cogn Affect Neurosci 2: 303-312.

Barr GA, Moriceau S, Shionoya K, Muzny K, Gao P, Wang S et al (2009). Transitions in infant learning are modulated by dopamine in the amygdala. Nat Neurosci 12: 1367-1369. 
Bick J, Zhu T, Stamoulis C, Fox NA, Zeanah CH, Nelson CA (2015). Effect of early institutionalization and foster care on long-term white matter development: a randomized clinical trial. JAMA Pediatr 169: 211-219.

Blair C, Raver CC (2012). Individual development and evolution: experiential canalization of self-regulation. Dev Psychol 48: 647.

Blasi A, Mercure E, Lloyd-Fox S, Thomson A, Brammer M, Sauter D et al (2011). Early specialization for voice and emotion processing in the infant brain. Curr Biol 21: 1220-1224.

Bock J, Riedel A, Braun K (2012). Differential changes of metabolic brain activity and interregional functional coupling in prefronto-limbic pathways during different stress conditions: functional imaging in freely behaving rodent pups. Front Cell Neurosci 6: 19.

Bowlby J (1969). Attachment and Loss. Volume l: Attachment. Basic Books: New York, NY. The classic theory of attachment is outlined in this chapter that theorizes about the neurobiology of infant-parent attachment and the importance of studying the developing organism.

Buss C, Davis EP, Shahbaba B, Pruessner JC, Head K, Sandman C (2012). Maternal cortisol over the course of pregnancy and subsequent child amygdala and hippocampus volumes and affective problems. Proc Natl Acad Sci USA 109: E1312-E1319.

Callaghan B, Richardson R (2012a). The effect of adverse rearing environments on persistent memories in young rats: removing the brakes on infant fear memories. Trans/ Psychiatry 2: e138.

Callaghan BL, Graham B, Li S, Richardson R (2013). From resilience to vulnerability: mechanistic insights into the effects of stress on transitions in critical period plasticity. Front Psychiatry 4: 90.

Callaghan BL, Howell B, Sullivan R, Tottenham N (2014a). The International Society for Developmental Psychobiology Sackler Symposium: early adversity and the maturation of emotion circuits - a cross-species analysis. Dev Psychobiol 56: 1635-1650. Comprehensive review of studies documenting accelerated sensitive period closure in emotion systems following early adversity across three species (rodent, monkey, human)

Callaghan BL, Li S, Richardson R (2014b). The elusive engram: what can infantile amnesia tell us about memory? Trends Neurosci 37: 47-53.

Callaghan BL, Richardson R (2011). Maternal separation results in early emergence of adult-like fear and extinction learning in infant rats. Behav Neurosci 125: 20-28.

Callaghan BL, Richardson R (2012b). Early-life stress affects extinction during critical periods of development: an analysis of the effects of maternal-separation on extinction in adolescent rats. Stress 15: 671-679.

Callaghan BL, Richardson R (2014). Early emergence of adult-like fear extinction in the rat following chronic corticosterone treatment of mother or pups. Behav Neurosci 128: 594-602.

Conner OL, Siegle GJ, McFarland AM, Silk JS, Ladouceur CD, Dahl RE et al (2012). Mom - it helps when you're right here! Attenuation of neural stress markers in anxious youths whose caregivers are present during fMRI. PLoS One 7: e50680.

Costafreda SG, Brammer MJ, David AS, Fu CHY (2008). Predictors of amygdala activation during the processing of emotional stimuli: a meta-analysis of 385 PET and fMRI studies. Brain Res Rev 58: 57-70.

Dadds MR, Hawes D (2006). Integrated Family Intervention for Child Conduct Problems: A behaviour-Attachment-Systems Intervention for Parents. Australian Academic Press: Bowen Hills, QLD.

Davis M (1992). The role of the amygdala in fear and anxiety. Annu Rev Neurosci 15 353-375.

de Gelder B, Terburg D, Morgan BE, Hortensius R, Stein DJ, van Honk J (2014). The role of human basolateral amygdala in ambiguous social threat perception. Cortex 52: 28-34.

Decety J, Michalska KJ, Kinzler KD (2012). The contribution of emotion and cognition to moral sensitivity: a neurodevelopmental study. Cerebral Cortex 22 209-220.

Dehaene-Lambertz G, Montavont A, Jobert A, Allirol L, Dubois J, Hertz-Pannier L et al (2010). Language or music, mother or Mozart? Structural and environmental influences on infants' language networks. Brain Lang 114: 53-65.

Diamond A (2000). Close interrelation of motor development and cognitive development and of the cerebellum and prefrontal cortex. Child Dev 71: 44-56.

Ditzen B, Neumann ID, Bodenmann G, von Dawans B, Turner RA, Ehlert $U$ et al (2007). Effects of different kinds of couple interaction on cortisol and heart rate responses to stress in women. Psychoneuroendocrinology 32: 565-574.

Donato F, Rompani SB, Caroni P (2013). Parvalbumin-expressing basket-cell network plasticity induced by experience regulates adult learning. Nature 504 272-276.

Egliston K-A, Rapee RM (2007). Inhibition of fear acquisition in toddlers following positive modelling by their mothers. Behav Res Ther 45: 1871-1882.

Ehrlich DE, Ryan SJ, Hazra R, Guo J-D, Rainnie DG (2013). Postnatal maturation of GABAergic transmission in the rat basolateral amygdala. J Neurophysiol 110: 926-941.
Ehrlich DE, Ryan SJ, Rainnie DG (2012). Postnatal development of electrophysiological properties of principal neurons in the rat basolateral amygdala. J Physio 590: 4819-4838

Freud S (1953). Three essays on the theory of sexuality. In: Strachey TJ (ed). The Standard Edition of the Complete Psychological Works of Sigmund Freud, Vol 7. The Hogarth Press: London.

Furmark T, Fischer H, Wik G, Larsson M, Fredrikson M (1997). The amygdala and individual differences in human fear conditioning. Neuroreport 8: 3957-3960.

Gabard-Durnam LJ, Flannery J, Goff B, Gee DG, Humphreys KL, Telzer E et al (2014). The development of human amygdala functional connectivity at rest from 4 to 23 years: a cross-sectional study. Neuroimage 95: 193-207.

Gabard-Durnam L, Gee DG, Goff B, Flannery J, Telzer E, Humphreys Ket al (2014). Hebbian-like mechanism for human amygdala-mPFC network development. Soc Neurosci Cogn Behav Nanosymp.

Gee D, Gabard-Durnam LJ, Flannery J, Goff B, Humphreys KL, Telzer EH et al (2013a). Early developmental emergence of mature human amygdala-prefrontal phenotype following maternal deprivation: evidence of stress-induced acceleration. Proc Natl Acad Sci USA 110: 15638-15643.

Gee DG, Gabard-Durnam LJ, Telzer EH, Humphreys KL, Goff B, Shapiro M et al (2014). Maternal buffering of human amygdala-prefrontal circuitry during childhood but not during adolescence. Psychol Sci 25: 2067-2078. Good paper for a demonstration of amygdala buffering by pictures of the parent via enhanced amygdala-mPFC connectivity.

Gee DG, Humphreys KL, Flannery J, Goff B, Telzer EH, Shapiro M et al (2013b). A developmental shift from positive to negative connectivity in human amygdalaprefrontal circuitry. J Neurosci 33: 4584-4593.

Gewirtz JL, Baer DM, Roth CH (1958). A note on the similar effects of low social availability of an adult and brief social deprivation on young children's behavior. Child Dev 29: 149-152.

Giedd JN, Vaituzis AC, Hamburger SD, Lange N, Rajapakse JC, Kaysen D et al (1996). Quantitative MRI of the temporal lobe, amygdala, and hippocampus in normal human development: ages 4-18 years. J Comp Neurol 366: 223-230. Comprehensive longitudinal analysis of gray matter across typical human development.

Gilmore JH, Shi F, Woolson SL, Knickmeyer RC, Short SJ, Lin W et al (2012). Longitudinal development of cortical and subcortical gray matter from birth to 2 years. Cereb Cortex 22: 2478-2485.

Gogolla N, Caroni P, Luthi A, Herry C (2009). Perineuronal nets protect fear memories from erasure. Science 325: 1258-1261. First demonstration that molecular signals that regulate sensitive period plasticity within the visual system also regulate sensitive period plasticity in emotion systems.

Graham AM, Fisher PA, Pfeifer JH (2013). What sleeping babies hear: a functional MRI study of interparental conflict and infants' emotion processing. Psychol Sci 24: 782-789.

Green JG, McLaughlin KA, Berglund PA, Gruber MJ, Sampson NA, Zaslavsky AM et al (2010). Childhood adversities and adult psychiatric disorders in the national comorbidity survey replication I: associations with first onset of DSM-IV disorders. Arch Gen Psychiatry 67: 113-123.

Gunnar MR, Brodersen L, Nachmias M, Buss K, Rigatuso J (1996). Stress reactivity and attachment security. Dev Psychobiol 29: 191-204.

Gunnar MR, Donzella B (2002). Social regulation of the cortisol levels in early human development. Psychoneuroendocrinology 27: 199-220.

Hahn A, Stein P, Windischberger C, Weissenbacher A, Spindelegger C, Moser $E$ et al (2011). Reduced resting-state functional connectivity between amygdala and orbitofrontal cortex in social anxiety disorder. Neuroimage 56: 881-889.

Hanson JL, Nacewiczc BM, Suttererd MJ, Cayob AA, Schaeferb SM, Rudolphe KD et al (2015). Behavioral problems after early life stress: contributons of the hippocampus and amygdala. Biol Psychiatry 4: 314-323.

Hare TA, Tottenham N, Galvan A, Voss HU, Glover GH, Casey BJ (2008). Biological substrates of emotional reactivity and regulation in adolescence during an emotional go-nogo task. Biol Psychiatry 63: 927-934.

Harmelech T, Preminger S, Wertman E, Malach R (2013). The day-after effect: long term, Hebbian-like restructuring of resting-state $\mathrm{fMRI}$ patterns induced by a single epoch of cortical activation. J Neurosci 33: 9488-9497.

Hensch TK (2005). Critical period mechanisms in developing visual cortex. Curr Top Dev Biol 69: 215-237

Hensch TK, Fagiolini M (2005). Excitatory-inhibitory balance and critical period plasticity in developing visual cortex. Prog Brain Res 147: 115-124. Excellent review of the mechanisms of sensitive period plasticity within the developing visual cortex

Hensch TK, Fagiolini M, Mataga N, Stryker MP, Baekkeskov S, Kash SF (1998). Local GABA circuit control of experience-dependent plasticity in developing visual cortex. Science 282: 1504-1508. 
Herman JP, Ostrander MM, Mueller NK, Figueiredo H (2005). Limbic system mechanisms of stress regulation: hypothalamo-pituitary-adrenocortical axis. Prog Neuropsychopharmacol Biol Psychiatry 29: 1201-1213.

Hibel LC, Granger DA, Blair C, Finegood ED (2014a). Maternal-child adrenocortical attunement in early childhood: continuity and change. Devel Psychobiol 57: 83-95.

Hibel LC, Trumbell JM, Mercado E (2014b). Work/non-workday differences in mother, child, and mother-child morning cortisol in a sample of working mothers and their children. Early Hum Devel 90: 1-7.

Hofer MA (1973a). Maternal separation affects infant rats' behavior. Behav Biol 9: 629-633

Hofer MA (1973b). The role of nutrition in the physiological and behavioral effects of early maternal separation on infant rats. Psychosom Med 35: 350-359.

Hofer MA (1994). Early relationships as regulators of infant physiology and behavior. Acta Paediatr 83: 9-18. Critical paper for anyone interested in the field of parental regulation of developing offspring systems.

Hostinar CE, Sullivan RM, Gunnar MR (2014). Psychobiological mechanisms underlying the social buffering of the hypothalamic-pituitary-adrenocortical axis: a review of animal models and human studies across development. Psychol Bull 140: 256. Timely and comprehensive review of the current state of research in social buffering across species. Essential reading for researchers interested in the field of social buffering or effect of social relationships of emotion, learning, and physiolgical reactivity

Huang CC, Chou PH, Yang CH, Hsu KS (2005). Neonatal isolation accelerates the developmental switch in the signalling cascades for long-term potentiation induction. J Physiol 569: 789-799.

Humphrey $T$ (1968). The development of the human amygdala during early embryonic life. J Comp Neurol 132: 135-165.

Karpova NN, Pickenhagen A, Lindholm J, Tiraboschi E, Kulesskaya N, Agustsdottir A et al (2011). Fear erasure in mice requires synergy between antidepressant drugs and extinction training. Science 334: 1731-1734.

Kernberg OF (1972). Early ego integration and object relations. Ann NY Acad Sci 193: 233-247.

Kim JH, Hamlin AS, Richardson R (2009). Fear extinction across development: the involvement of the medial prefrontal cortex as assessed by temporary inactivation and immunohistochemistry. J Neurosci 29: 10802-10808.

Kim JH, Li S, Richardson R (2011). Immunohistochemical analyses of long-term extinction of conditioned fear in adolescent rats. Cereb Cortex 21: 530-538.

Kim MJ, Whalen PJ (2009). The structural integrity of an amygdala-prefrontal pathway predicts trait anxiety. J Neurosci 29: 11614-11618.

Kirschbaum C, Klauer T, Filipp S-H, Hellhammer DH (1995). Sex-specific effects of social support on cortisol and subjective responses to acute psychological stress. Psychosom Med 57: 23-31.

Krettek JE, Price JL (1978). A description of the amygdaloid complex in the rat and cat with observations on intra-amygdaloid axonal connections. J Comp Neurol 178: 255-279.

Kwon J-T, Nakajima R, Kim H-S, Jeong Y, Augustine GJ, Han J-H (2014). Optogenetic activation of presynaptic inputs in lateral amygdala forms associative fear memory. Learn Mem 21: 627-633.

LaBar KS, Gatenby JC, Gore JC, LeDoux JE, Phelps EA (1998). Human amygdala activation during conditioned fear acquisition and extinction: a mixed-trial fMRI study. Neuron 20: 937-945.

LeDoux JE (1994). Emotion, memory and the brain. Sci Am 270: 50-57.

LeDoux JE (2000). Emotion circuits in the brain. Annu Rev Neurosci 23: 155-184.

LeDoux JE, Iwata J, Cicchetti P, Reis DJ (1988). Different projections of the central amygdaloid nucleus mediate autonomic and behavioral correlates of conditioned fear. J Neurosci 8: 2517-2529.

Lenroot RK, Giedd JN (2006). Brain development in children and adolescents: insights from anatomical magnetic resonance imaging. Neurosci Biobehav Rev 30: 718-729.

Lewis CM, Baldassarre A, Committeri G, Romani GL, Corbetta M (2009). Learning sculpts the spontaneous activity of the resting human brain. Proc Natl Acad Sci 106: $17558-17563$.

Lickliter R (2004). Premature visual stimulation accelerates intersenory functioning in bobwhite quail neonates. Dev Psychobiol 23: 15-27.

Luby J, Belden A, Botteron K, Marrus N, Harms MP, Babb C et al (2013). The effects of poverty on childhood brain development: the mediating effect of caregiving and stressful life events. JAMA Pediatr 167: 1135-1142.

Lupien SJ, McEwen BS, Gunnar MR, Heim C (2009). Effects of stress throughout the lifespan on the brain, behaviour and cognition. Nat Rev Neurosci 10: 434-445. Elegant model of the differing effects of stress applied at different developmental stages. Fundamental reading for persons interested in understanding the effect of stress across the lifespan and in concepts of developmental trajectory more generally.

Mackey AP, Miller Singley AT, Bunge SA (2013). Intensive reasoning training alters patterns of brain connectivity at rest. J Neurosci 33: 4796-4803.
McCallum J, Kim JH, Richardson R (2010). Impaired extinction retention in adolescent rats: effects of d-cycloserine. Neuropsychopharmacology 35: 2134-2142.

McDonald A, Mascagni F, Guo L (1996). Projections of the medial and lateral prefrontal cortices to the amygdala: Phaseolus vulgaris leucoagglutinin study in the rat. Neuroscience 71: 55-75.

McEwen BS (2004). Protection and damage from acute and chronic stress: allostasis and allostatic overload and relevance to the pathophysiology of psychiatric disorders. Ann NY Acad Sci 1032: 1-7.

McEwen BS, Morrison JH (2013). The brain on stress: vulnerability and plasticity of the prefrontal cortex over the life course. Neuron 79: 16-29.

McGee AW, Yang Y, Fischer QS, Daw NW, Strittmatter SM (2005). Experiencedriven plasticity of visual cortex limited by myelin and Nogo receptor. Science 309: 2222-2226.

McLaughlin KA, Green JG, Gruber MJ, Sampson NA, Zaslavsky AM, Kessler RC (2010). Childhood adversities and adult psychiatric disorders in the national comorbidity survey replication II: associations with persistence of DSM-IV disorders. Arch Gen Psychiatry 67: 124-132.

McRae K, Gross JJ, Weber J, Robertson ER, Sokol-Hessner P, Ray RD et al (2012). The development of emotion regulation: an $\mathrm{fMRI}$ study of cognitive reappraisal in children, adolescents and young adults. Soc Cogn Affect Neurosci 7: 11-22.

Middlemiss W, Granger DA, Goldberg WA, Nathans L (2012). Asynchrony of mother-infant hypothalamic-pituitary-adrenal axis activity following extinction of infant crying responses induced during the transition to sleep. Early Hum Dev 88: 227-232.

Milad MR, Orr SP, Lasko NB, Chang Y, Rauch SL, Pitman RK (2008). Presence and acquired origin of reduced recall for fear extinction in PTSD: results of a twin study. J Psychiatric Res 42: 515-520.

Milad MR, Pitman RK, Ellis CB, Gold AL, Shin LM, Lasko NB et al (2009). Neurobiological basis of failure to recall extinction memory in posttraumatic stress disorder. Biol Psychiatry 66: 1075-1082.

Milad MR, Quinn BT, Pitman RK, Orr SP, Fischl B, Rauch SL (2005). Thickness of ventromedial prefrontal cortex in humans is correlated with extinction memory. Proc Natl Acad Sci USA 102: 10706-10711.

Milad MR, Quirk GJ (2002). Neurons in medial prefrontal cortex signal memory for fear extinction. Nature 420: 70-74.

Milad MR, Rauch SL, Pitman RK, Quirk GJ (2006). Fear extinction in rats: implications for human brain imaging and anxiety disorders. Biol Psychology 73: 61-71.

Milad MR, Wright Cl, Orr SP, Pitman RK, Quirk GJ, Rauch SL (2007). Recall of fear extinction in humans activates the ventromedial prefrontal cortex and hippocampus in concert. Biol Psychiatry 62: 446-454.

Monk CS, Telzer EH, Mogg K, Bradley BP, Mai X, Louro H et al (2008). Amygdala and ventrolateral prefrontal cortex activation to masked angry faces in children and adolescents with generalized anxiety disorder. Arch Gen Psychiatry 65: 568-576.

Moore WE 3rd, Pfeifer JH, Masten CL, Mazziotta JC, lacoboni M, Dapretto M (2012). Facing puberty: associations between pubertal development and neural responses to affective facial displays. Soc Cogn Affect Neurosci 7: 35-43.

Moriceau S, Roth TL, Okotoghaide T, Sullivan RM (2004). Corticosterone controls the developmental emergence of fear and amygdala function to predator odors in infant rat pups. Int J Dev Neurosci 22: 415-422.

Moriceau S, Shionoya K, Jakubs K, Sullivan RM (2009). Early-life stress disrupts attachment learning: the role of amygdala corticosterone, locus ceruleus corticotropin releasing hormone, and olfactory bulb norepinephrine. J Neurosci 29: 15745-15755. Excellent mechanistic paper outlining pathways through which rearing stress may lead to early closure of the sensitive period for fear learning in the rodent.

Moriceau S, Sullivan RM (2004). Unique neural circuitry for neonatal olfactory learning. J Neurosci 24: 1182-1189.

Moriceau S, Sullivan RM (2006). Maternal presence serves as a switch between learning fear and attraction in infancy. Nat Neurosci 9: 1004-1006.

Moriceau S, Wilson DA, Levine S, Sullivan RM (2006). Dual circuitry for odor-shock conditioning during infancy: corticosterone switches between fear and attraction via amygdala. J Neurosci 26: 6737-6748.

Morris JS, Ohman A, Dolan RJ (1998). Conscious and unconscious emotional learning in the human amygdala. Nature 393: 467-470.

Mosconi MW, Cody-Hazlett H, Poe MD, Gerig G, Gimpel-Smith R, Piven J (2009). Longitudinal study of amygdala volume and joint attention in 2- to 4-year-old children with autism. Arch Gen Psychiatry 66: 509-516.

Motzkin JC, Philippi CL, Wolf RC, Baskaya MK, Koenigs M (2015). Ventromedial prefrontal cortex is critical for the regulation of amygdala activity in humans. Biol Psychiatry 77: 276-284.

Nabel EM, Morishita H (2013). Regulating critical period plasticity: insight from the visual system to fear circuitry for therapeutic interventions. Front Psychiatry 4: 146. 
Nachmias M, Gunnar M, Mangelsdorf S, Parritz RH, Buss K (1996). Behavioral inhibition and stress reactivity: the moderating role of attachment security. Child Dev 67: 508-522.

Nordahl CW, Scholz R, Yang X, Buonocore MH, Simon T, Rogers S et al (2012). Increased rate of amygdala growth in children aged 2 to 4 years with autism spectrum disorders: a longitudinal study. Arch Gen Psychiatry 69: 53-61.

Ochsner KN, Bunge SA, Gross JJ, Gabrieli JD (2002). Rethinking feelings: an FMRI study of the cognitive regulation of emotion. J Cogn Neurosci 14: 1215-1229.

Ono M, Kikusui T, Sasaki N, Ichikawa M, Mori Y, Murakami-Murofushi K (2008). Early weaning induces anxiety and precocious myelination in the anterior part of the basolateral amygdala of male Balb/c mice. Neuroscience 156: 1103-1110.

Papp LM, Pendry P, Adam EK (2009). Mother-adolescent physiological synchrony in naturalistic settings: within-family cortisol associations and moderators. J Fam Psychol 23: 882.

Paus T (2005). Mapping brain maturation and cognitive development during adolescence. Trends Cogn Sci 9: 60-68.

Payne C, Machado CJ, Bliwise NG, Bachevalier J (2010). Maturation of the hippocampal formation and amygdala in Macaca mulatta: a volumetric magnetic resonance imaging study. Hippocampus 20: 922-935.

Phelps EA, Delgado MR, Nearing KI, LeDoux JE (2004). Extinction learning in humans: role of the amygdala and vmPFC. Neuron 43: 897-905.

Phelps EA, LeDoux JE (2005). Contributions of the amygdala to emotion processing: from animal models to human behavior. Neuron 48: 175-187.

Phillips ML, Drevets WC, Rauch SL, Lane R (2003a). Neurobiology of emotion perception I: the neural basis of normal emotion perception. Biol Psychiatry 54: 504-514.

Phillips ML, Drevets WC, Rauch SL, Lane R (2003b). Neurobiology of emotion perception II: implications for major psychiatric disorders. Biol Psychiatry 54: 515-528.

Qiu A, Anh TT, Li Y, Chen H, Rifkin-Graboi A, Broekman BFP et al (2015). Prenatal maternal depression alters amygdala functional connectivity in 6-month-old infants. Trans/ Psychiatry 5: e508.

Quirk GJ, Likhtik E, Pelletier JG, Paré D (2003). Stimulation of medial prefrontal cortex decreases the responsiveness of central amygdala output neurons. J Neurosci 23: 8800-8807.

Quirk GJ, Russo GK, Barron JL, Lebron K (2000). The role of ventromedial prefrontal cortex in the recovery of extinguished fear. J Neurosci 20: 6225-6231.

Rilling JK, Winslow JT, O'Brien D, Gutman DA, Hoffman JM, Kilts CD (2001). Neural correlates of maternal separation in rhesus monkeys. Biol Psychiatry 49: 146-157.

Roeber BJ, Gunnar MR, Pollak SD (2014). Early deprivation impairs the development of balance and bilateral coordination. Dev Psychobiol 56: 1110-1118.

Sananes CB, Campbell BA (1989). Role of the central nucleus of the amygdala in olfactory heart rate conditioning. Behav Neurosci 103: 519-525.

Sarkar S, Craig MC, Dell'Acqua F, O'Connor TG, Catani M, Deeley Q et al (2014). Prenatal stress and limbic-prefrontal white matter microstructure in children aged 6-9 years: a preliminary diffusion tensor imaging study. World J Biol Psychiatry 15 346-352.

Schumann CM, Hamstra J, Goodlin-Jones BL, Lotspeich LJ, Kwon H, Buonocore $\mathrm{MH}$ et al (2004). The amygdala is enlarged in children but not adolescents with autism; the hippocampus is enlarged at all ages. J Neurosci 24: 6392-6401.

Scott S, Dadds MR (2009). Practitioner review: when parent training doesn't work: theory-driven clinical strategies. J Child Psychol Psychiatry 50: 1441-1450.

Scott SK, Young AW, Calder AJ, Hellawell DJ, Aggleton JP, Johnsons M (1997). Impaired auditory recognition of fear and anger following bilateral amygdala lesions. Nature 385: 254-257

Seltzer LJ, Prososki AR, Ziegler TE, Pollak SD (2012). Instant messages vs. speech: hormones and why we still need to hear each other. Evol Hum Behav 33: 42-45.

Seltzer LJ, Ziegler TE, Pollak SD (2010). Social vocalizations can release oxytocin in humans. Proc R Soc B Biol Sci 277: 2661-2666.

Sierra-Mercado D, Padilla-Coreano N, Quirk GJ (2010). Dissociable roles of prelimbic and infralimbic cortices, ventral hippocampus, and basolateral amygdala in the expression and extinction of conditioned fear. Neuropsychopharmacology 36: $529-538$.

Silvers JA, Shu J, Hubbard AD, Weber J, Ochsner KN (2014). Concurrent and lasting effects of emotion regulation on amygdala response in adolescence and young adulthood. Dev Sci 18: 771-784.

Sorce JF, Emde RN, Campos JJ, Klinnert MD (1985). Maternal emotional signaling: its effect on the visual cliff behavior of 1-year-olds. Devel Psychol 21: 195.

Spangler G, Schieche M (1998). Emotional and adrenocortical responses of infants to the strange situation: the differential function of emotional expression. Int $\mathrm{J}$ Behav Dev 22: 681-706.
Sullivan RM, Landers M, Yeaman B, Wilson DA (2000). Neurophysiology: good memories of bad events in infancy. Nature 407: 38-39.

Sullivan RM, Wilson DA (1993). Role of the amygdala complex in early olfactory associative learning. Behav Neurosci 107: 254-263.

Swartz JR, Carrasco M, Wiggins JL, Thomason ME, Monk CS (2014). Age-related changes in the structure and function of prefrontal cortex-amygdala circuitry in children and adolescents: a multi-modal imaging approach. Neuroimage 86: 212-220.

Terburg D, Morgan BE, Montoya ER, Hooge IT, Thornton HB, Hariri AR et al (2012). Hypervigilance for fear after basolateral amygdala damage in humans. Trans/ Psychiatry 2: e115

Timmer SG, Urquiza AJ (2014). Empirically Based Treatments for Maltreated Children: A Developmental Perspective. Handbook of Child Maltreatment. Springer: New York, NY, pp 351-376

Tottenham N (2012). Human amygdala development in the absence of speciesexpected caregiving. Dev Psychobiol 54: 594-611.

Tottenham N (2014). The importance of early experiences for neuro-affective development. In: Andersen SL, Pine DS (eds), The Neurobiology of Childhood, Vol 16, Springer: Berlin, Heidelberg, pp 109-129.

Tottenham N, Hare TA, Quinn BT, McCarry TW, Nurse M, Gilhooly T et al (2010a). Prolonged institutional rearing is associated with atypically large amygdala volume and difficulties in emotion regulation. Dev Sci 13: 46-61.

Tottenham N, Hare TA, Quinn BT, McCarry TW, Nurse M, Gilhooly T et al (2010b). Prolonged institutional rearing is associated with atypically large amygdala volume and difficulties in emotion regulation. Dev Sci 13: 46-61.

Tottenham N, Sheridan MA (2009). A review of adversity, the amygdala and the hippocampus: a consideration of developmental timing. Front Hum Neurosci 3: 68.

Tottenham N, Sheridan MA (2010). A review of adversity, the amygdala and the hippocampus: a consideration of developmental timing. Front Hum Neurosci 3 68 (doi:10.3389/neuro.09.068.2009).

Uematsu A, Matsui M, Tanaka C, Takahashi T, Noguchi K, Suzuki M et al (2012). Developmental trajectories of amygdala and hippocampus from infancy to early adulthood in healthy individuals. PLoS One 7: e46970.

Ulfig N, Setzer M, Bohl J (2003). Ontogeny of the human amygdala. Annals of the New York Academy of Science 985: 22-33.

Urry HL, van Reekum CM, Johnstone T, Kalin NH, Thurow ME, Schaefer HS et al (2006). Amygdala and ventromedial prefrontal cortex are inversely coupled during regulation of negative affect and predict the diurnal pattern of cortisol secretion among older adults. J Neurosci 26: 4415-4425

Veening JG, Swanson LW, Sawchenko PE (1984). The organization of projections from the central nucleus of the amygdala to brainstem sites involved in central autonomic regulation: a combined retrograde transport-immunohistochemical study. Brain Res 303: 337-357.

Vink M, Derks JM, Hoogendam JM, Hillegers M, Kahn RS (2014). Functional differences in emotion processing during adolescence and early adulthood. Neuroimage 91: 70-76.

Wang S, Tudusciuc O, Mamelak AN, Ross IB, Adolphs R, Rutishauser U (2014). Neurons in the human amygdala selective for perceived emotion. Proc Natl Acad Sci 111: E3110-E3119.

Werker JF, Hensch TK (2015). Critical periods in speech perception: new directions. Annu Rev Psychol 66: 173-196. Excellent review of the current state of research on the intersection between nonhuman and human studies in sensitive periods, especially as they relate to human language learning.

Whalen PJ (1998). Fear, vigilance, and ambiguity: initial neuroimaging studies of the human amygdala. Curr Direct Psychol Sci 7: 177-188.

Whittle S, Dennison M, Vijayakumar N, Simmons JG, Yücel M, Lubman DI et al (2013). Childhood maltreatment and psychopathology affect brain development during adolescence. J Am Acad Child Adolesc Psychiatry 52: 940-952.e941.

Whittle S, Lichter R, Dennison M, Vijayakumar N, Schwartz O, Byrne ML et al (2014). Structural brain development and depression onset during adolescence: a prospective longitudinal study. Am J Psychiatry 171: 564-571.

Wiesel TN, Hubel DH (1963). Single-cell responses in striate cortex of kittens deprived of vision in one eye. J Neurophysiol 26: 1003-1017. Critical paper outlining the primary model of sensitive period plasticity: ocular dominance plasticity in the visual cortex.

Wota A, Byrne C, Murray I, Ofuafor T, Nisar Z, Neuner F et al (2014). An examination of childhood trauma in individuals attending an adult mental health service. Irish $\mathrm{J}$ Psycholog Med 31: 259-270.

Zeanah C, Egger H, Smyke A, Nelson C, Fox N, Marshall P et al (2009). Institutional rearing and psychiatric disorders in Romanian preschool children. Am J Psychiatry 166: 777-785. 